\title{
On Friendly Index Set of Graphs
}

\author{
M. Teffilia ${ }^{1^{*}}$ and J. Devaraj ${ }^{2}$ \\ ${ }^{1}$ Department of Mathematics, Nesamony Memorial Christian College, Marthandam,Tamilnadu, India \\ ${ }^{2}$ Department of Mathematics, Nesamony Memorial Christian College, Marthandam,Tamilnadu, India \\ (Affiliated to Manonmaniam Sundaranar University, Abishekapatti, \\ Thirunelveli, Tamil Nadu, India) \\ *Corresponding author: teffiliafranklin@gmail.com
}

Available online at: www.isroset.org

Accepted 18/Aug/2018, Online 30/Aug/2018

\begin{abstract}
A function f from $\mathrm{V}(\mathrm{G})$ to $\{0,1\}$ where for each edge $\mathrm{xy}, \mathrm{f}^{*}(\mathrm{xy})=(\mathrm{f}(\mathrm{x})+\mathrm{f}(\mathrm{y}))(\bmod 2)$, let $\mathrm{v}_{\mathrm{i}}(\mathrm{f})$ is the number of vertices $v$ with $f(v)=i$ and $e_{i}(f)$ is the number of edges e with $f *(e)=i$ is called friendly if $\left|v_{0}(f)-v_{1}(f)\right| \leq 1$. The friendly index set of a graph $G$ is $F I(G)=\left\{\left|e_{0}(f)-e_{1}(f)\right|\right.$, where $f$ runs over all friendly labelings $f$ of $\left.G\right\}$. In this paper we find the friendly index set of the umbrella graph, $\operatorname{Spl}\left(\mathrm{K}_{1, \mathrm{n}}\right)$, Globe graph, $\mathrm{P}_{2}+\mathrm{mk}_{1}$ and union of a path and a star sharing a vertex in common.
\end{abstract}

Keywords - Friendly labeling, Friendly index set, Umbrella graph, Spl $\left(K_{l, n}\right)$, Globe graph

\section{INTRODUCTION}

For all terminology and notations in graph theory we follow harary[3]. Unless mentioned or otherwise a graph in this paper shall mean a simple finite graph without isolated vertices. Let $G$ be a graph with vertex set $V(G)$ and edge set $E(G)$. A labeling $f: V(G) \rightarrow Z_{2}$ induces an edge labeling $f^{*}: E(G) \rightarrow Z_{2}$ defined by $f^{*}(x y)=f(x)+f(y)$ for each edge $\quad x y \in E(G)$. For $i \in Z_{2}$, let $\mathrm{v}_{\mathrm{f}}(\mathrm{i})=\operatorname{card}\{\mathrm{v} \in \mathrm{V}(\mathrm{G}): \mathrm{f}(\mathrm{v})=\mathrm{i}\}$ and $\mathrm{e}_{\mathrm{f}}(\mathrm{i})=\operatorname{card}\left\{\mathrm{e} \in \mathrm{E}(\mathrm{G}): \mathrm{f}^{*}(\mathrm{e})\right.$ $=\mathrm{i}$ \}. A labeling $\mathrm{f}$ of a graph $\mathrm{G}$ is said to be friendly if $\left|v_{f}(0)-v_{f}(1)\right| \leq 1$. The friendly index set of the graph $G$, $\mathrm{FI}(\mathrm{G})$ is defined as $\left\{\left|\mathrm{e}_{\mathrm{f}}(0)-\mathrm{e}_{\mathrm{f}}(1)\right|\right.$ : the vertex labeling $\mathrm{f}$ is friendly\}. Lee and $\mathrm{Ng}$ [3] define the friendly index set of graphs. This is a generalization of graph cordiality.

This paper consists of four sections. Section I is the introduction part of friendly index set. Section II contains preliminaries and notations.Section III contains main results and illustrations and section IV contains conclusion part .

\section{PRELIMINARIES AND NOTATIONS}

Definition 2.1[4] : A graph labeling is an assignment of integers to the vertices or edges or both subject to certain conditions.

Definition 2.2 [10] : A fan graph $\mathrm{f}_{\mathrm{n}}$ obtained by joining all vertices of a path $P_{n}$ to further vertex, called the centre. Thus $\mathrm{f}_{\mathrm{n}}$ contains $\mathrm{n}+1$ vertices $c, \mathrm{v}_{1}, \mathrm{v}_{2}, \ldots, \mathrm{v}_{\mathrm{n}}$ and $(2 \mathrm{n}-1)$ edges say $\mathrm{cv}_{\mathrm{i}}, 1 \leq \mathrm{i} \leq \mathrm{n}$ and $\mathrm{v}_{\mathrm{i}} \mathrm{v}_{\mathrm{i}+1}, 1 \leq \mathrm{i} \leq \mathrm{n}-1$
Definition 2.3 [2] : Star $\mathrm{K}_{1, \mathrm{n}}$ is the graph with one vertex of degree $\mathrm{n}$ called apex and $\mathrm{n}$ vertices of degree one.

Definition 2.4[7] : A Umbrella graph $\mathrm{U}(\mathrm{m}, \mathrm{n})$ is the graph obtained by joining a path $\mathrm{P}_{\mathrm{n}}$ with the central vertex of a fan $\mathrm{f}_{\mathrm{m}}$.

Definition 2.5 [5] : For each vertex v of a graph $G$ take a new vertex $v$. Join $v_{1}$ to all the vertices of $G$ adjacent to $v$. The graph $\operatorname{spl}(\mathrm{G})$ thus obtained is called splitting graph of $\mathrm{G}$.

Definition 2.6 [6] : A globe is a graph obtained from two isolated vertex are joined by $n$ paths of length two. It is denoted by $\mathrm{Gl}(\mathrm{n})$

\section{MAIN RESULTS}

Theorem 3.1 : The Umbrella graph $U(m, n)$ where $n=2$ has the friendly index set $\{0,2,4, \ldots, m+1\}$ if $m$ is odd, $m \geq 9$ and $\{0,2,4, \ldots, m\}$ if $\mathrm{m}$ is even, $\mathrm{m} \geq 4$

\section{Proof:}

Let $\mathrm{G}=\mathrm{U}(\mathrm{m}, 2)$

The vertex set of $\mathrm{U}(\mathrm{m}, 2)$ is $\mathrm{V}(\mathrm{G})=\left\{\mathrm{x}_{1}, \mathrm{x}_{2}, \ldots, \mathrm{x}_{\mathrm{m}}, \mathrm{y}_{1}, \mathrm{y}_{2}\right\}$ The edge set of $U(m, 2)$ is

$\mathrm{E}(\mathrm{G})=\left\{\left(\mathrm{x}_{\mathrm{i}}, \mathrm{x}_{\mathrm{i}+1}\right) \mid 1 \leq \mathrm{i} \leq \mathrm{m}-1\right\} \cup\left\{\left(\mathrm{y}_{1}, \mathrm{y}_{2}\right)\right\} \cup\left\{\left(\mathrm{x}_{\mathrm{i}}, \mathrm{y}_{1}\right), 1 \leq \mathrm{i} \leq \mathrm{m}\right\}$ Then $|\mathrm{V}(\mathrm{G})|=\mathrm{m}+2,|\mathrm{E}(\mathrm{G})|=2 \mathrm{~m}$

Case (i) : $\mathrm{m}$ is odd 
First label alternatively with 0 's and 1 's starting with 0 in $\mathrm{x}_{\mathrm{i}}$ 's and label $\mathrm{y}_{1}$ by 1 and $\mathrm{y}_{2}$ by 0 . Then $\mathrm{v}(0)-\mathrm{v}(1)=1$ and $\mid \mathrm{e}(0)-$ $\mathrm{e}(1) \mid=\mathrm{m}+1$

Next interchange only $\mathrm{y}_{1}$ and $\mathrm{y}_{2}$. Then $\mathrm{v}(0)-\mathrm{v}(1)=1$ and $|\mathrm{e}(0)-\mathrm{e}(1)|=\mathrm{m}-1$.

Next label $x_{1}$ by ' 0 ' and next two vertices by ' 1 ' and following next two vertices by ' 0 ' and then alternatively by 0 's and 1's starting with ' 1 ' and label $\mathrm{y}_{1}$ by 1 and $\mathrm{y}_{2}$ by 0 . Then $|\mathrm{v}(0)-\mathrm{v}(1)|=1$ and $|\mathrm{e}(0)-\mathrm{e}(1)|=\mathrm{m}-3$.

Then interchange only $\mathrm{y}_{1}$ and $\mathrm{y}_{2}$. Again $|\mathrm{v}(0)-\mathrm{v}(1)|=1$ and $|e(0)-e(1)|=m-5$.

Next label $\mathrm{x}_{1}$ by 0 and next three vertices by 1 and following next three vertices by 0 and then alternatively by 0 's and 1 's starting with 1 . Then label $\mathrm{y}_{1}$ by 1 and $\mathrm{y}_{2}$ by 0 . Then $\mid \mathrm{v}(0)-$ $\mathrm{v}(1) \mid=1$ and $|\mathrm{e}(0)-\mathrm{e}(1)|=\mathrm{m}-9$.

Continuously proceeding like this ie, label $\mathrm{x}_{1}$ by 0 and next continuously label up to $\frac{m-3}{2}$ vertices by 1 and $\frac{m-3}{2}$ vertices by 0 and then alternatively 0 's and 1's starting with 1 .

At the last step we get the vertex is labeled friendly and $|\mathrm{e}(0)-\mathrm{e}(1)|=0$.

$\therefore$ The friendly index set is $\{0,2,4, \ldots, \mathrm{m}+1\}$

Case (ii) : $m$ is even

Fix $\mathrm{y}_{1}$ by 1 and $\mathrm{y}_{2}$ by 0 .

Label the vertices $\mathrm{x}_{1}, \mathrm{x}_{2}, \ldots, \mathrm{x}_{\mathrm{m}}$ alternatively by 0 's and 1 's starting with ' 0 '. Therefore the vertex labeling is friendly and $|\mathrm{e}(0)-\mathrm{e}(1)|=\mathrm{m}$.

Keep $\mathrm{x}_{1}$ and $\mathrm{x}_{2}$ remain unchanged and then label all the other vertices ie, $x_{3}, x_{4}, \ldots, x_{m}$ by their complement. Then the vertex labeling is friendly and $|e(0)-e(1)|=m-2$.

Then keep $\mathrm{x}_{1}, \mathrm{x}_{2}, \mathrm{x}_{3}, \mathrm{x}_{4}$ remain unchanged and then label all the other vertices ie, $x_{5}, x_{6}, \ldots, x_{m}$ by its complement. Again the vertex labeling is friendly and $|\mathrm{e}(0)-\mathrm{e}(1)|=\mathrm{m}-4$.

Continue this process to get the friendly index set $\{2,4, \ldots, \mathrm{m}\}$

Atlast change the labels $\mathrm{x}_{\mathrm{m}}$ and $\mathrm{y}_{1}$ to its complement and we get the vertex is friendly and $|e(0)-e(1)|=0$.

$\therefore$ The friendly index set is $\{0,2,4, \ldots, \mathrm{m}\}$.

Illustration 3.1 :

$\mathrm{FI}(\mathrm{U}(9,2))=\{0,2,4,6,8,10\}$

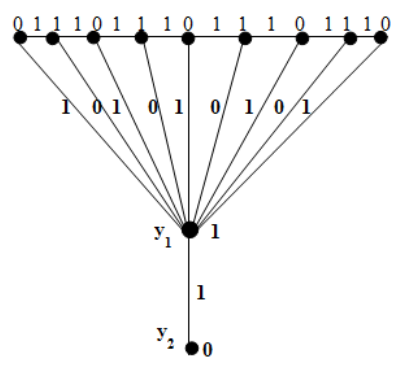

$$
|e(0)-e(1)|=10
$$
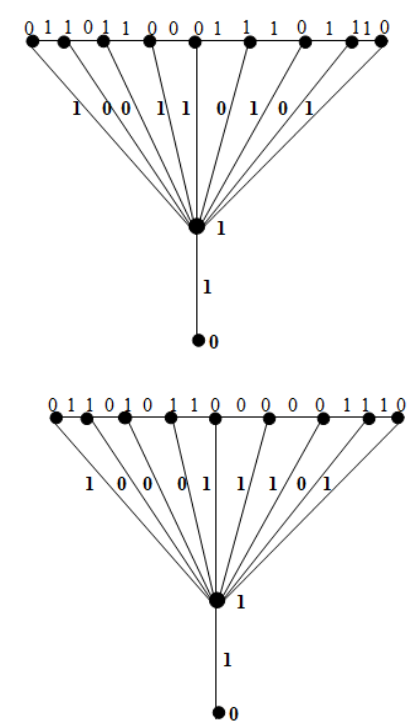

$|e(0)-e(1)|=2$

$\mathrm{FI}(\mathrm{U}(8,2))=\{0,2,4,6,8\}$
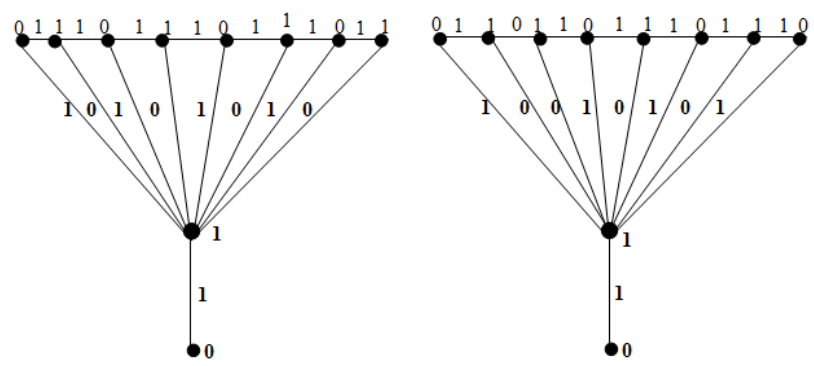

$|e(0)-e(1)|=8$

$|e(0)-e(1)|=6$ 


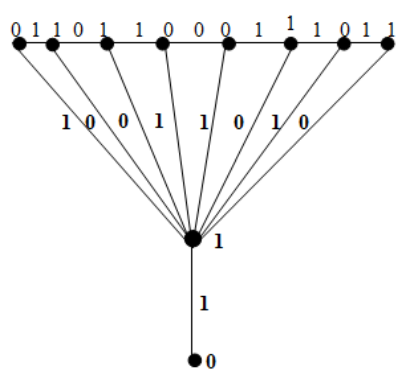

$|e(0)-e(1)|=4$

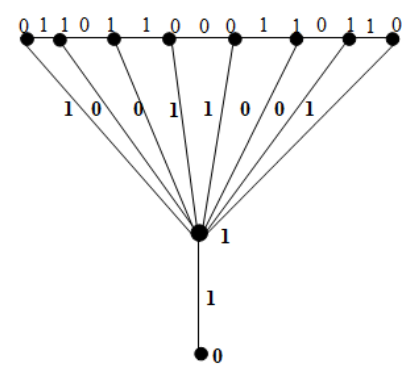

$|e(0)-e(1)|=2$

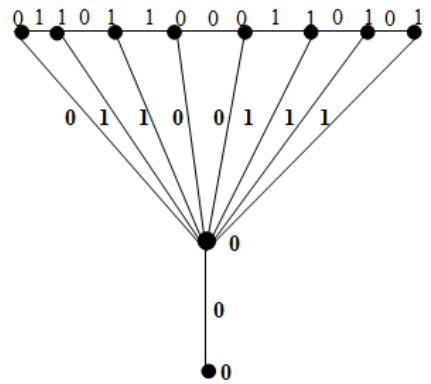

$|e(0)-e(1)|=0$

\section{Theorem 3.2 :}

The friendly index set of $\operatorname{spl}\left(\mathrm{k}_{1, \mathrm{n}}\right)$ is $\{0,2,4, \ldots, \mathrm{n}\}$, if $\mathrm{n}$ is even and $\{1,3, \ldots, n\}$, if $\mathrm{n}$ is odd.

\section{Proof :}

Let $\mathrm{v}_{1}, \mathrm{v}_{2}, \ldots, \mathrm{v}_{\mathrm{n}}$ be the pendant vertices, $\mathrm{v}$ be the apex vertex of $\mathrm{K}_{1, \mathrm{n}}$ and $\mathrm{u}, \mathrm{u}_{1}, \mathrm{u}_{2}, \ldots \mathrm{u}_{\mathrm{n}}$ are the added vertices corresponding to $\mathrm{v}, \mathrm{v}_{1}, \mathrm{v}_{2}, \ldots, \mathrm{v}_{\mathrm{n}}$ in $\operatorname{spl}\left(\mathrm{k}_{1, \mathrm{n}}\right)$

Let $\mathrm{V}(\mathrm{G})=\left\{\mathrm{v}, \mathrm{v}_{1}, \mathrm{v}_{2}, \ldots, \mathrm{v}_{\mathrm{n}}, \mathrm{u}, \mathrm{u}_{1}, \mathrm{u}_{2}, \ldots, \mathrm{u}_{\mathrm{m}}\right\}$

$\mathrm{E}(\mathrm{G})=\left\{\mathrm{vv}_{\mathrm{i}} / 1 \leq \mathrm{i} \leq \mathrm{n}\right\} \cup\left\{\mathrm{uu}_{\mathrm{i}} / 1 \leq \mathrm{i} \leq \mathrm{n}\right\} \cup\left\{\mathrm{uv}_{\mathrm{i}} / 1 \leq \mathrm{i} \leq \mathrm{n}\right\}$

Thus spl $\left(\mathrm{k}_{1, \mathrm{n}}\right)$ has $2 \mathrm{n}+2$ vertices and $3 \mathrm{n}$ edges.

Case (i)

When $\mathrm{n}$ is even

Fix $u=0$ and $v=1$

First label the vertices $v_{i}$ 's as $(0,0, \ldots, 0)$ and $u_{i}$ 's as $(1,1, \ldots, 1)$ in $\operatorname{spl}(\mathrm{k} 1, \mathrm{n})$. Then the vertex labeling is friendly and $\mathrm{e}(0)$ $\mathrm{e}(1) \mid=\mathrm{n}$

In next step decrease one vertex labeling ie, ' 0 ' from $v_{i}$ 's and label with its complement ie, ' 1 . Also decrease one vertex labeling, ie ' 1 ' from $\mathrm{u}_{\mathrm{i}}$ 's and label with its complement ie, ' 0 '. Again the vertex labeling is friendly and $|\mathrm{e}(0)-\mathrm{e}(1)|=$ n-2

The vertices remain unchanged and continue the above step upto $\left(\frac{n}{2}\right)$ vertices having the label 0 in $\mathrm{v}_{\mathrm{i}}$ 's and $\left(\frac{n}{2}\right)$ vertices having the label 1 in $\mathrm{u}_{\mathrm{i}}$ 's.

$\therefore$ The friendly index set is $\{0,2,4, \ldots, \mathrm{n}\}$

\section{Case (ii)}

When $n$ is odd

Fix $\mathrm{u}=0$ and $\mathrm{v}=1$

First label the vertices $v_{i}$ 's as $(0,0, \ldots, 0)$ and $u_{i}$ 's as $(1,1, \ldots, 1)$ in $\operatorname{spl}\left(\mathrm{k}_{1, \mathrm{n}}\right)$. Then the vertex labeling is friendly and $\mathrm{e}(0)-$ $\mathrm{e}(1) \mid=\mathrm{n}$

In the next step decrease one vertex labeling ie ' 0 ' from $\mathrm{v}_{\mathrm{i}}$ 's and label with its complement ie, ' 1 '. Also decrease one vertex labeling ie ' 1 ' from $u_{i}$ 's and label with its complement ie, ' 0 '. Again the vertex labeling is friendly and $|e(0)-e(1)|=$ n-2

All changed vertex remain unchanged and continue this process upto $\left[\frac{n}{2}\right]$ vertices having the label 1 in $\mathrm{v}_{\mathrm{i}}$ 's and $\left[\frac{n}{2}\right]$ vertices having the label 0 in $u_{i}$ 's.

$\therefore$ The friendly index set is $\{1,3, \ldots, \mathrm{n}\}$

\section{Illustration 3.2}

When $\mathrm{n}$ is even

FI $\left(\operatorname{Spl}\left(\mathrm{k}_{1,4}\right)\right)=\{0,2,4\}$

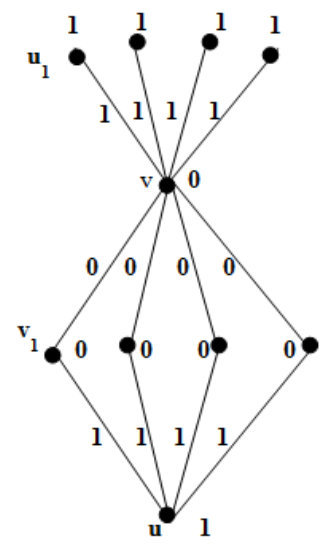

$|e(0)-e(1)|=4$

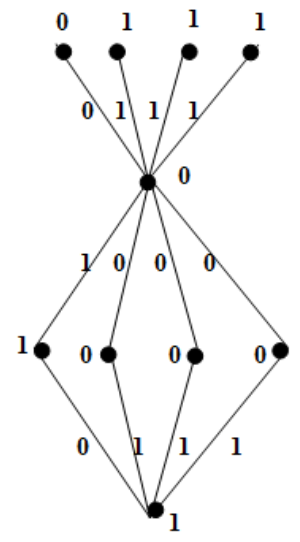

$|e(0)-e(1)|=2$ 


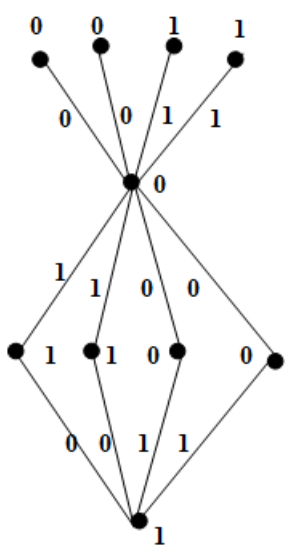

$|e(0)-e(1)|=0$

when $n$ is odd

FI $\left(\operatorname{Spl}\left(\mathrm{k}_{1,5}\right)\right)=\{1,3,5\}$

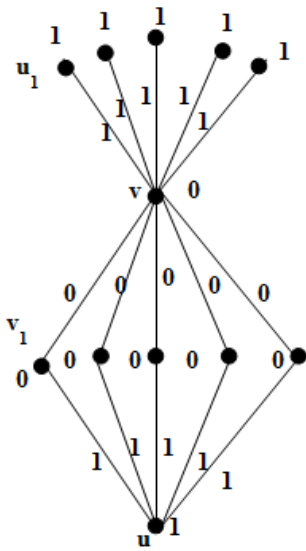

$|e(0)-e(1)|=5$

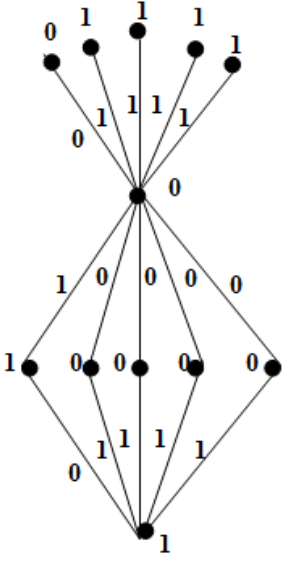

$|e(U)-e(1)|=s$

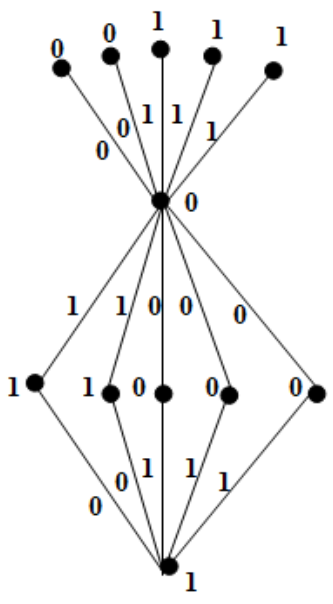

$|e(0)-e(1)|=1$

\section{Theorem 3. 3 :}

$\mathrm{FI}(\mathrm{Gl}(\mathrm{n}))=\{0,4\}$, if $\mathrm{n}$ is even and $\mathrm{FI}(\mathrm{Gl}(\mathrm{n}))=\{0,2,6\}$, if $\mathrm{n}$ is odd

\section{Proof :}

Let $\left(\mathrm{x}_{1}, \mathrm{x}_{2}, \ldots, \mathrm{x}_{\mathrm{n}}\right)$ be the vertices of $\mathrm{n}$ paths of length two. Let $\mathrm{u}, \mathrm{v}$ be the vertices which are joined by those $\mathrm{n}$ paths.

It has $\mathrm{n}+2$ vertices and $2 \mathrm{n}$ edges.

Case(i) : When $n$ is even

Label $\mathrm{u}$ by 0 and $\mathrm{v}$ by 1 and label $\left(\frac{n}{2}\right)$ vertices of $\mathrm{x}_{\mathrm{i}}$ 's by 0 and other $\left(\frac{n}{2}\right)$ vertices by 1 . Then $\mathrm{v}(0)-\mathrm{v}(1)=0$. Therefore $|e(0)-e(1)|=0$

Next label $\mathrm{u}$ and $\mathrm{v}$ by 0 and label $\left(\frac{n}{2}\right)-1$ vertices of $\mathrm{x}_{\mathrm{i}}$ 's by 0 and $\left(\frac{n}{2}\right)+1$ vertices of $x_{i}$ 's by 1 . Again $v(0)-v(1)=0$. Then $|\mathrm{e}(0)-\mathrm{e}(1)|=4$

Then the friendly index set is $\{0,4\}$

Case (ii) : When $n$ is odd

Label $\mathrm{u}$ and $\mathrm{v}$ by 0 and label $\left[\frac{n}{2}\right]$ vertices of $\mathrm{x}_{\mathrm{i}}$ 's by 0 and the remaining vertices by 1 . Then the vertex labeling is friendly with $\mathrm{v}(0)-\mathrm{v}(1)=1$. Therefore $|\mathrm{e}(0)-\mathrm{e}(1)|=2$.

Next Label $u$ by 0 and $v$ by 1 and label $\left[\frac{n}{2}\right]+1$ vertices of $\mathrm{x}_{\mathrm{i}}$ 's by 0 and the remaining vertices by 1 .

Then $\mathrm{v}(0)-\mathrm{v}(1)=1$. Therefore $|\mathrm{e}(0)-\mathrm{e}(1)|=0$.

Next label $\mathrm{u}$ and $\mathrm{v}$ by 1 and label $\left[\frac{n}{2}\right]+2$ vertices of $\mathrm{x}_{\mathrm{i}}$ 's by 0 and the remaining vertices by 1 . Again $\mathrm{v}(0)-\mathrm{v}(1)=1$ and $|e(0)-e(1)|=6$.

Then the friendly index set is $\{0,2,6\}$

Illustration 3.3

$\mathrm{FI}(\mathrm{Gl}(4))=\{0,4\}$
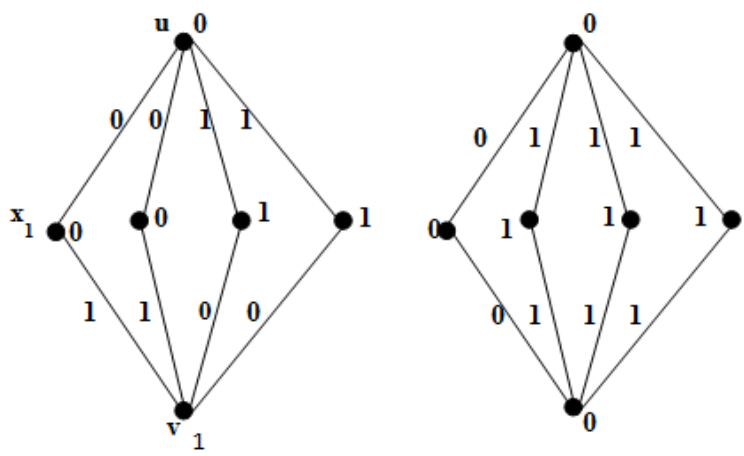

$|e(0)-e(1)|=0$

$|e(0)-e(1)|=4$ 
$\mathrm{FI}(\mathrm{Gl}(5))=\{0,2,6\}$
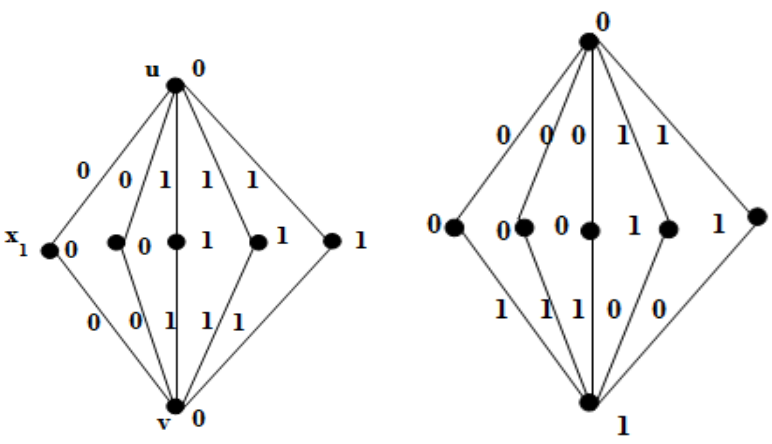

$|e(0)-e(1)|=2$

$|e(0)-e(1)|=0$

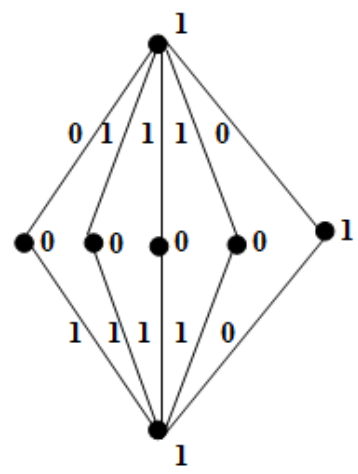

$|e(0)-e(1)|=6$

\section{Theorem 3.4 :}

$\mathrm{FI}\left(\mathrm{P}_{2}+\mathrm{mk}_{1}\right)=\{1,3\}$, if $\mathrm{m}$ is even and $\mathrm{FI}\left(\mathrm{P}_{2}+\mathrm{mk}_{1}\right)=\{1,5\}$ if $\mathrm{m}$ is odd.

Proof :

Consider a path $\mathrm{P}_{2}$ with two vertices $\mathrm{v}_{1}, \mathrm{v}_{2}$. Let $\mathrm{y}_{1}, \mathrm{y}_{2}, \ldots, \mathrm{y}_{\mathrm{m}}$ be the $\mathrm{m}$ isolated vertices. Join $\mathrm{v}_{1}, \mathrm{v}_{2}$ with $\mathrm{y}_{\mathrm{i}}, 1 \leq \mathrm{i} \leq \mathrm{m}$. The graph obtained is $P_{2}+m_{1}$. The vertex set of $G$ is $V(G)=$ $\left\{\mathrm{v}_{1}, \mathrm{v}_{2}, \mathrm{y}_{1}, \mathrm{y}_{2}, \ldots, \mathrm{y}_{\mathrm{m}}\right\}$. The edge set of $\mathrm{G}$ is

$\mathrm{E}(\mathrm{G})=\left\{\left(\mathrm{v}_{1} \mathrm{v}_{2}\right)\right\} \cup\left\{\left(\mathrm{v}_{1} \mathrm{y}_{\mathrm{i}}\right) \mid 1 \leq \mathrm{i} \leq \mathrm{m}\right\} \cup\left\{\left(\mathrm{v}_{2} \mathrm{y}_{\mathrm{i}}\right) \mid 1 \leq \mathrm{i} \leq\right.$ $\mathrm{m}\}$

Then $|\mathrm{V}(\mathrm{G})|=2+\mathrm{m}$ and $|\mathrm{E}(\mathrm{G})|=2 \mathrm{~m}+1$

First consider an even $\mathrm{m}$

Label $\mathrm{v}_{1}$ and $\mathrm{v}_{2}$ as 0 and $y_{\frac{m}{2}}, y_{\frac{m}{2}+1}, \ldots \ldots y_{m}$ as 1 and the remaining vertices as 0 . Then the vertex labeling is friendly with $\mathrm{v}(1)-\mathrm{v}(0)=0$ and $|\mathrm{e}(1)-\mathrm{e}(0)|=3$.

Then label $\mathrm{v}_{1}$ as 0 and $\mathrm{v}_{2}$ as 1 and label the vertices of $\mathrm{y}_{\mathrm{i}}$ as alternatively 0 and 1 . This vertex labeling is also friendly with $\mathrm{v}(1)-\mathrm{v}(0)=0$ Then $|\mathrm{e}(0)-\mathrm{e}(1)|=1$.

$\therefore$ The friendly index set is $\{1,3\}$.
Next consider an odd $m$.

Label $\mathrm{v}_{1}$ and $\mathrm{v}_{2}$ as 0 and $y_{\left[\frac{m}{2}\right]+1}, \ldots . . \mathrm{y}_{\mathrm{m}}$ as 1 and all the remaining vertices as 0 . This labeling is friendly with $\mathrm{v}(0)-\mathrm{v}(1)=1$. Then $|\mathrm{e}(0)-\mathrm{e}(1)|=1$.

Then label $\mathrm{v}_{1}$ and $\mathrm{v}_{2}$ as 0 and label $y_{\left[\frac{m}{2}\right]} \ldots . \mathrm{y}_{\mathrm{m}}$ as 1 and all the remaining vertices as 0 . This labeling is also friendly with $\mathrm{v}(1)-\mathrm{v}(0)=1$ Then $|\mathrm{e}(0)-\mathrm{e}(1)|=5$

$\therefore$ The friendly index set is $\{1,5\}$.

\section{Illustration 3.4}

$\mathrm{FI}\left(\mathrm{P}_{2}+6 \mathrm{~K}_{1}\right)=\{1,3\}$

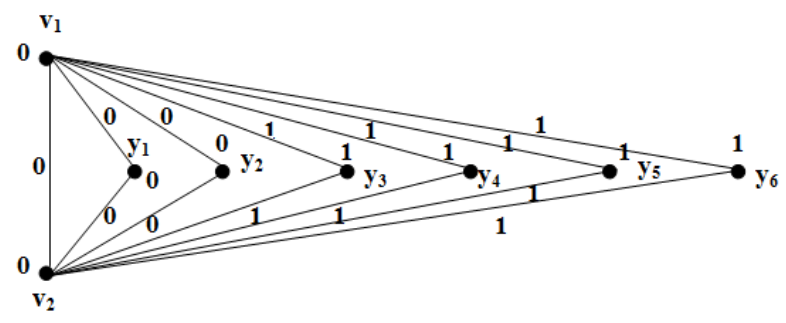

$|e(0)-e(1)|=3$

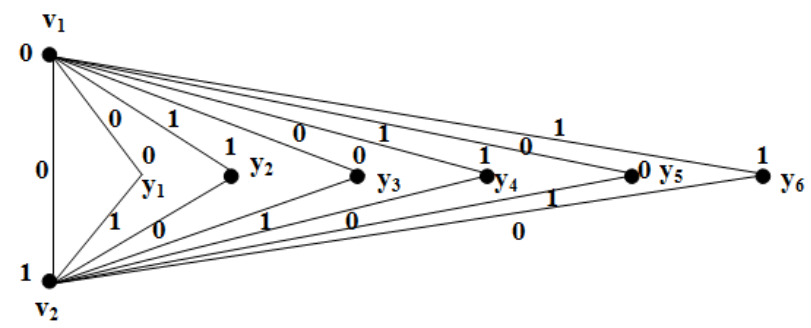

$|e(0)-e(1)|=1$

FI $\left(\mathrm{P}_{2}+5 \mathrm{~K}_{1}\right)=\{1,5\}$

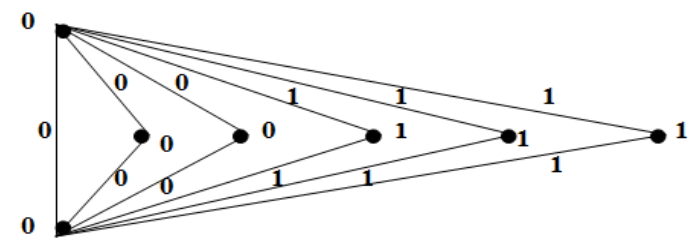

$|e(0)-e(1)|=1$

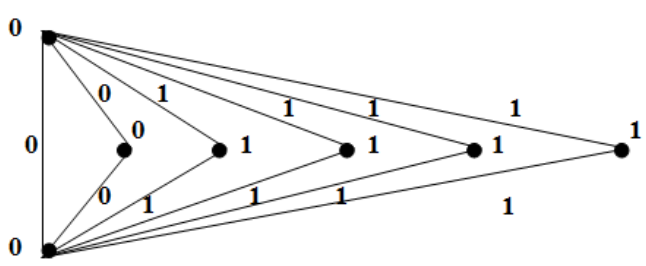

$|e(0)-e(1)|=5$ 


\section{Theorem 3.5 :}

Union of a path and a star sharing a vertex in common has the friendly index set $\{1,3,5, \ldots . .2 \mathrm{n}-5\}$

\section{Proof}

Let the $n$ vertices of path $P_{n}$ be $u_{1}, u_{2}, \ldots ., u_{n}$. Let the $n$ spokes of star $S_{n}$ be $v_{1}, v_{2}, \ldots . v_{n}$ and $u_{1}$ be the centre vertex of the star. Identify $\mathrm{u}_{1}$ and $\mathrm{v}_{1}$. Let the graph so obtained is $\mathrm{G}$.

Clearly $\mathrm{G}$ has $2 \mathrm{n}$ vertices and $2 \mathrm{n}-1$ edges.

First label $\left(\mathrm{u}_{1}, \quad \mathrm{u}_{2}, \mathrm{u}_{3} \ldots \mathrm{u}_{\mathrm{n}}\right)=(1,0,0, \ldots \ldots 0)$ and $\left(\mathrm{v}_{1}, \mathrm{v}_{2}, \ldots . \mathrm{v}_{\mathrm{n}}\right)=(0,1,1, \ldots \ldots .1)$ The vertex labeling is friendly and $|\mathrm{e}(0)-\mathrm{e}(1)|=2 \mathrm{n}-5$

Now keep all the vertex remain unchanged. Next change the vertex $\mathrm{u}_{2}$ and $\mathrm{v}_{2}$ to its complement. This labeling is friendly. Then $|\mathrm{e}(0)-\mathrm{e}(1)|=2 \mathrm{n}-3$

Now keep all the vertex remains unchanged and change the vertex $\mathrm{u}_{3}$ and $\mathrm{v}_{3}$ to its complement. This labeling is vertex friendly. Then $|\mathrm{e}(0)-\mathrm{e}(1)|=2 \mathrm{n}-1$

Continue this process upto changing the vertex $\mathrm{u}_{n-2}$ and $\mathrm{v}_{n-2}$ to its complement.

Then the friendly index set is $\{1,3,5, \ldots \ldots \ldots, 2 \mathrm{n}-5\}$

\section{Illustration 3.5 :}
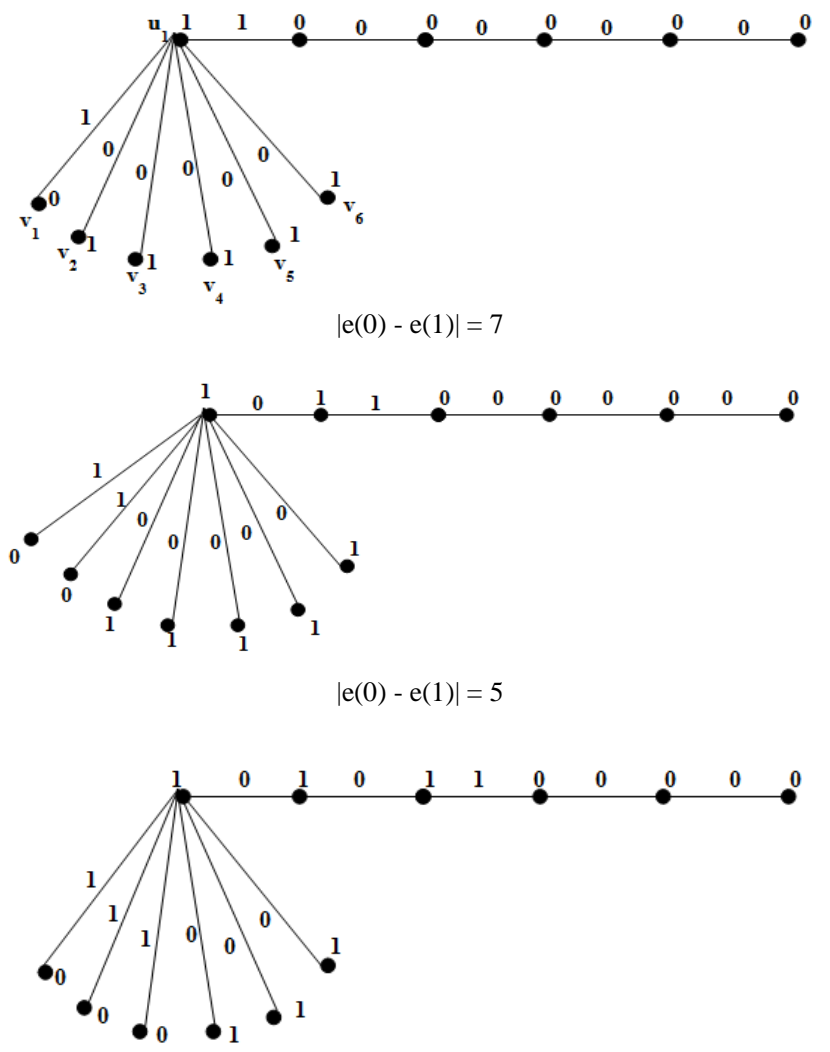

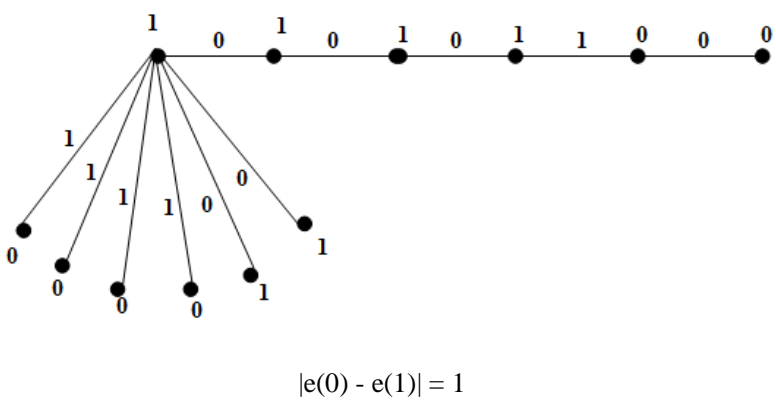

\section{CONCLUSION}

Labeling of graphs in graph theory is one of the interesting research topic in the recent days. Here we have find new results of friendly index sets of five graphs related to labeling of graphs. Similar work can be carried out for other graphs also.

\section{REFERENCES}

[1] J. Devaraj and M. Teffilia, "On Harmonious graphs", Bulletin of pure and applied sciences, Vol 37E (math and stat), No. 1, p.p. 4753, 2018.

[2] G.V. Ghodasara and D.G. Adalja, "Divisor Cordial labeling for vertex switching and duplication of special graphs", International Journal of mathematics and its applications, Vol 4, Issue 3-B, pp 73-80, 2016.

[3] F. Harary, Graph theory, Narosa publishing House, 1969.

[4] Joseph A. Gallian, "A dynamic survey of graph labeling", The electronic Journal of combinatorics, 2015.

[5] P. Lawrence Rofario Raj and S. Koilraj graph of some standard graphs, "Cordial labeling for the splitting graph of some standard graphs", International Journal of Mathematics and self computing, Vol 1, pp. 105 - 114, 2011.

[6] A. Nellai Murugan and G. Devakiruba "Cycle related Divisor Cordial graphs", International Journal of Mathematics Trends and technology - Volume 12, Number 1, 2014.

[7] G. Sankari and S. lavanya, " Odd -even graceful labeling of Umbrella and tadpole graphs", International Journal of pure and applied mathematics, Vol 114, No. 6, pp. 139 - 143, 2017.

[8] Sin - Min Lee, Ho-Kuen Ng and Gee-choon Lau, "On friendly index sets of spiders", Malaysian Journal of Mathematical sciences, 8(1) : pp. 47-68, 2014.

[9] Yong - song Ho, Sin-Min Lee, Ho-Kuen Ng, "On friendly index sets of root unions of stars by cycles", Journal of Combinatorial mathematics and Combinatorial Computing, 62, pp. 97-120, 2007.

[10] Dr. K. Vaithilingam, "Difference labeling of some graph families", International Journal of mathematics and statistics Invention, $\mathrm{Vol}$ 2, Issue 6, pp 37 - 43, 2014.

$|e(0)-e(1)|=3$ 